\title{
PKM PELATIHAN PEMBUATAN MEDIA AUDIO VISUAL PADA GURU PAUD INKLUSI UNTUK SISWA DOWN SYNDROME DI KECAMATAN SITUBONDO
}

\section{PKM TRAINING FOR MAKING AUDIO VISUAL MEDIA IN INCLUSION TEACHERS FOR DOWN SYNDROME STUDENTS IN SITUBONDO DISTRICT}

\author{
Amalia Risqi Puspitaningtyas \\ Fakultas Keguruan dan Ilmu Pendidikan \\ Universitas Abdurachman Saleh Situbondo \\ amaliarisqipuspitaningtyas@gmail.com
}

\begin{abstract}
Abstrak : Pengabdian yang dilakukan bertujuan untuk menambah pemahaman, kemampuan ketrampilan seorang guru dalam pemberian materi pembelajaran yang inovatif bagi siswa khususnya siswa down syndrome.Media pembelajaran memiliki peranan yang penting dalam kegiatan belajarmengajar,dalam proses belajar mengajar guru tidak bisa menyamakan antara mengajar anak normal dengan anak berkebutuhan khusus, karena kebutuhan keduanya sangat berbeda dalam pembelajaran. Anak berkebutuhan khusus perlu cara khusus terkait pemberian materi, sehingga guru harus selektif dalam menggunakan media pembelajaran. Materi pembelajaran bagi anak down syndrome memerlukan kreativitas yang ekstra dan media pembelajaran yang benar-benar menarik agar potensi yang sudah ada pada anak dapat berkembang lebih optimal, karena anak down syndrome memiliki kelainan fisik. Metode yang digunakan yaitu tiga tahapan diantaranya tahap persiapan, tahapan pelaksanaan dan tahap tindak lanjut kegiatan. Untuk megupayakan peningkatan dalam pemahaman materi terkait pengenalan huruf maka haruslah guru diberikan pelatihan dalam media pembelajaran. Kegiatan pelatihan ini memberikan pembinaan bagi guru PAUD Inklusi untuk mengembangkan media pembelajaran yang inovatif bagi anak down syndrome pelatihan ini dilaksanakan kurang lebih satu bulan. Selama pelatihan guru sangat antusias dalam mengikuti pelatihan ini dan diberi kesempatan dalam berdisukusi dan bertanya kepada narasumber jika ada permasalahan untuk mencapai solusi yang tepat. Luaran yang diharapkan dari penelitian ini guru paud dapat membuat media pembeljaran yang lebih inovatif dan kreatif.
\end{abstract}

Kata Kunci : Media Audio Visual, Down Syndrome, Guru PAUD, Inklusi

Abstract : The service provided aims to increase understanding, the ability of a teacher's skills in providing innovative learning material for students, especially students with Down Syndrome. Learning media have an important role in teaching and learning activities, in teaching and learning process teachers cannot equate between teaching normal children with children with needs specifically, because the needs of the two are very different in learning. Children with special needs need special ways related to the provision of material, so teachers must be selective in using learning media. Learning 


\section{INTEGRITAS : Jurnal Pengabdian}

Vol 4, No 1, Juli 2020

ISSN 2580 - 7978 (cetak) ISSN 2615 - 0794 (online)

materials for children with Down syndrome require extra creativity and learning media that are really interesting so that the potential that already exists in children can develop more optimally, because children with Down syndrome have physical abnormalities. The method used is three stages including the preparation phase, the implementation phase and the follow-up phase of the activity. In order to improve the understanding of material related to letter recognition, the teacher must be given training in instructional media. This training activity provides guidance for PAUD Inclusive teachers to develop innovative learning media for children with Down syndrome. This training is held for approximately one month. During the training the teacher was very enthusiastic in participating in this training and was given the opportunity to discuss and ask the speakers if there were problems to reach the right solution. The expected outcome of this research is that paud teachers can make learning media more innovative and creative.

Keywords : Audio Visual Media, Down Syndrome, PAUD Teachers, Inclusion

\section{PENDAHULUAN}

Anak dengan downsyndrome mengalami kesulitan dalam hal-hal yang berhubungan dengan belajar karena kemampuan atensi, metacognition, memory, dan generalisasi yang lambat dibandingkan dengan anak normal.Masalah ini dapat berasal dari lemahnya kemampuan persepsi dan menilai (judgement) suatu ingatan yang sudah disimpan dengan keadaan saat ini. Anak down syndrome memiliki perbedaan tingkat kecerdasan yang rendah yaitu bagian fisik khusunya alat ucap yang kurang sempurna, baik secara langsung maupun tidak langsung yang dapat mempengaruhi dalam komunikasi anak down syndrome. Hal yang membedakan dari siswa lainnya karena kelainan kromosom yang mengakibatkan fisik siswa down syndrome berbeda salah satunya yaitu pengucapan siswa down syndrome tidak begitu jelas seperti orang cadel dan kata yang diucapkan hanya kata yang diujungnya saja.Kemampuan dalam menggunakan ingatan jangka pendek yang lemah pada anak down syndrome. Salah satu ciri anak down syndrome adalah perkembangan bahasa yang miskin dankekurang mampuan umum untuk mengadakan komunikasi verbal.Di antara kemampuan inteligensi, kemampuan berinteraksi dan kemampuan berbahasa, kemampuan berbahasa menduduki golongan terendah.Kelemahan perkembangan berbahasa ini dinyatakan dalam bentuk kekurangan perbendaharaan kata-kata, kelemahan artikulasi, kebiasaan untuk berbicara dengan mempergunakan kata-kata yang terpisah. 


\section{INTEGRITAS : Jurnal Pengabdian}

Vol 4, No 1, Juli 2020

ISSN $2580-7978$ (cetak) ISSN 2615 - 0794 (online)

Salah satu permasalahan yang dimiliki oleh anak berkebutuhan khusus, khususnya anak down syndrome maka Guru PAUD harus memahami permasalahn perkembangan anak yang bersifat nonnormatif atau berkelainan. Guru PAUD dituntut untuk dapat mengenali setiap ciri permasalahan dalam perkembangan anak yang berkelainan, sehingga dapat memberikan pembelajaran yang tepat. Dalam peningkatan berbahasa siswa disekolah peranan media sebagai alat bantu menjadi sangat penting dalam membantu aktivitas proses pembelajaran baik di dalam kelas maupun di luar kelas terutama membantu peningkatan hasil belajar. Pengajaran membaca tidak akan berhasil kecuali jika guru mengetahui metode dan media yang tepat dan dapat digunakan pada saat mengajarkan anak membaca. Metode yang dapat digunakan adalah metode yang menyenangkan bagi anak dengan cara bermain. Bagi anak usia dini, belajar adalah bermain. Selain metode, guru pun harus memperhatikan media yang digunakan dalam kegiatan belajar mengajar.

Media pembelajaran memiliki peranan yang penting dalam kegiatan belajarmengajar. Media pembelajaran merupakan alat bantu yang memudahkan guru dalam menyampaikan materi pelajaran kepada siswa terutama pada siswa berkebutuhan khusus. Media yang digunakan harus menggunakan pendekatan audio dan visual agar anak tidak merasa jenuh ketika kegiatan pembelajaran. Dari hasil keterangan dari kepala sekolah paud inklusi terdapat beberapa anak yang mengalami down syndrome.Meski sekolah tersebut sebagai sekolah Inklusi akan tetapi dalam pelaksanaan belajar mengajar masih kurang maksimal dikarenakan latar belakang guru yang bukan dari lulusan Pendidikan Luar Biasa (PLB) atau Pendidikan Luar sekolah (PLS) dikarenakan di Kabupaten situbondo belum ada guru yang berlatar belakang sarjana S-1 PLS/ PLB, sehingga dalam proses belajar mengajar dalam menyampaian materi guru mengalami kendala oleh anak berkebutuhan khusus, khususnya anak down syndrome.Guru pendamping pada umumnya merasa kebinggunan dalam dalam menghadapi siswa ketika dalam proses belajar mengajar. Mereka tidak mengetahui perilaku apa yang harus diberikan kepada siswanya yang berkebutuhan khusus terutama anak down 


\section{INTEGRITAS : Jurnal Pengabdian}

Vol 4, No 1, Juli 2020

ISSN 2580 - 7978 (cetak) ISSN 2615 - 0794 (online)

syndrome ketika penjelasan yang diberikan oleh guru tidak bisa di pahami oleh mereka. Hal ini terjadi karena guru belum memiliki wawasan mengenai anak berkebutuhan khusus, meskipun sekolah tersebut sudah dijadikan sekolah inklusi tetapi kebanyakan guru tidak mendapatkan pengetahuan cara penanganan sesuai kebutuhan anak berkebutuhan khusus. Di PAUD Inklusi tersebut teradapat anak bebrapa anak berkebutuhan khusus yaitu anak tuna rungu, down syndrome, autis, hiperaktif. Akan tetapi siswa berkebutuhan khusus di sekolah tersebut yang paling banyak yaitu anak down syndrome. Anak down syndrome memiliki Kesulitan berinteraksi dengan orang lain terutama dialami oleh penyandang down syndrome anak-anak. Anak down syndrome mengalami kesulitan dalam belajar berbicara dan menangkap sinyal kontak dengan orang lain sehinga akan lebih lambat belajar dibandingkan dengan anak berkebutuhan khusus lainnya.

Kegiatan PKM ini dilakukan pada guru PAUD Inklusi kecamatan situbondo. Kegiatan ini di maksudkan untuk memotivasi guru dalam mendidikan anak berkebutuhan khusus di sekolah tersebut agar dalam pelaksanaan kegiatan belajar dan mengajar secara lebih efektif dan inovatif. Di samping itu agar para guru dalam mengajar mau melakukan inovasi- inovasi sebagai bagian dari tugas profesionalismenya.Media pembelajaran memiliki peranan yang penting dalam kegiatan belajar mengajar. Media pembelajaran merupakan alat bantu yang memudahkan guru dalam menyampaikan materi pelajaran kepada siswa. Media yang digunakan harus menggunakan pendekatan audio dan visual agar anak tidak merasa jenuh ketika kegiatan pembelajaran.Audio Visual di disajikan dalam bentuk gambar, animasi, video, suara/bunyi dan permainan warna dapat menimbulkan ketertarikan pada siswa untukbelajar dan akhirnya anak dapat mengenal huruf dan dapat membaca tanpa merasa dipaksa dan tidak membosankan.Penggunaan media dapat membantu guru dalam menyampaikan pembelajaran terhadap anak berkebutuhan khusus.

Media pembelajaran Audio visual didapatkan hasil bahwa sebagian besar anak belum memiliki kemampuan dalam membaca permulaan.Metode membaca 


\section{INTEGRITAS : Jurnal Pengabdian}

Vol 4, No 1, Juli 2020

ISSN $2580-7978$ (cetak) ISSN 2615 - 0794 (online)

di sajikan langsung dari guru menggunakan papan tulis menyebabkan kurangnya interaksi dalam pembelajaran membaca. Pengajaran membaca tidak akan berhasil kecuali jika guru mengetahui metode dan media yang tepat dan dapat digunakan pada saat mengajarkan anak membaca.Media pembelajaran audio visual bagi anak down syndrome yang dikembangkan diharapkan mampu memfasilitasi siswa untuk bisa menerima pembelajaran yang di berikan oleh guru dengan lebih mudah sehingga proses dan hasil belajar yang didapat dicapai dengan lebih baik.

Pengajaran membaca tidak akan berhasil kecuali jika guru mengetahui metode dan media yang tepat dan dapat digunakan pada saat mengajarkan anak membaca. Sesuai dengan karakteristk anak usia dini yang bersifat aktif dalam berekplorasi de gan lingkungn sekitar, oleh sebab itu aktifitas bermain adalah bagian dari proses pebelajaran, begitu juga dengan anak downsyndrome. Media audio visual mengambangkan permulaan membaca anak dan dapat menambah kosa kata bagi anak downsyndrome karena anak berinteraksi dengan teman, belajar berkomunikasi dan mengembangan daya imajinasi anak. Hal tersebut sesuai pemaparan yang dismpaikan oleh Smith $(2006 ; 119)$ yang menyatakan anak yang mengalami keterbelakangan mnetal mungkin mengalmi kesulitan yang besar dalam mempelajari materi yang abstrak, cara- cara pengajaran yang memakai metri kongkrit serta contoh- contoh yang jelas mungkin sangat efektif dalam membantu proses pembelajaran.Dalam pelaksanaan pembelajaran dengan menggunkan media audio visual anak downsyndrome dapat menirukan kalimat sederhana semisal mengenal huruf dengan baik dan dapat menyebutkan simbolsimbol huruf yang dikenal. Media audio visual juga dipandang sebagai media yang sesuai dengan kebutuhan anak down syndrome karena anak down syndrome mengalami kesulitan dalam belajar berbicara dan menangkap sinyal kontak dengan orang lain sehinga akan lebih lambat belajar dibandingkan dengan anak berkebutuhan khusus lainnya. 


\section{INTEGRITAS : Jurnal Pengabdian}

\section{ISSN 2580 - 7978 (cetak) ISSN 2615 - 0794 (online)}

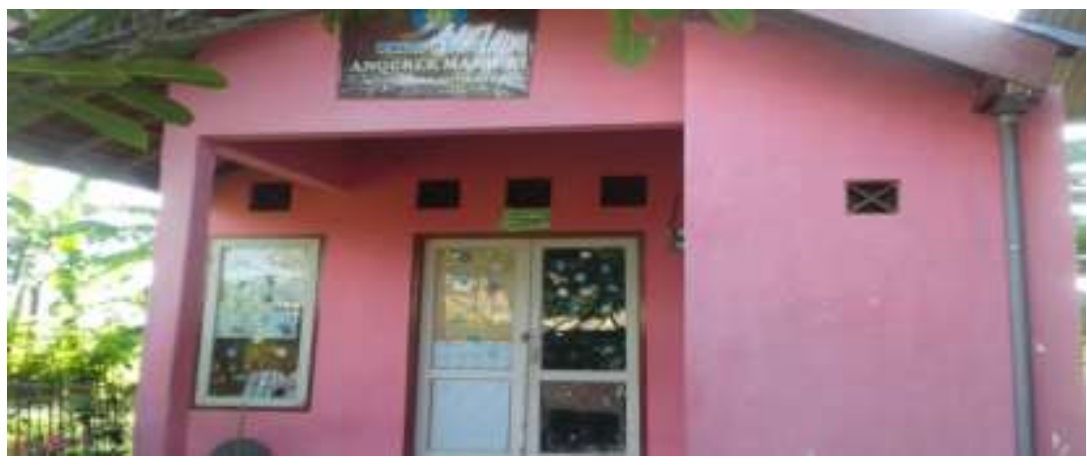

Gambar1. PAUD Inklusi

\section{PERMASALAHAN MITRA}

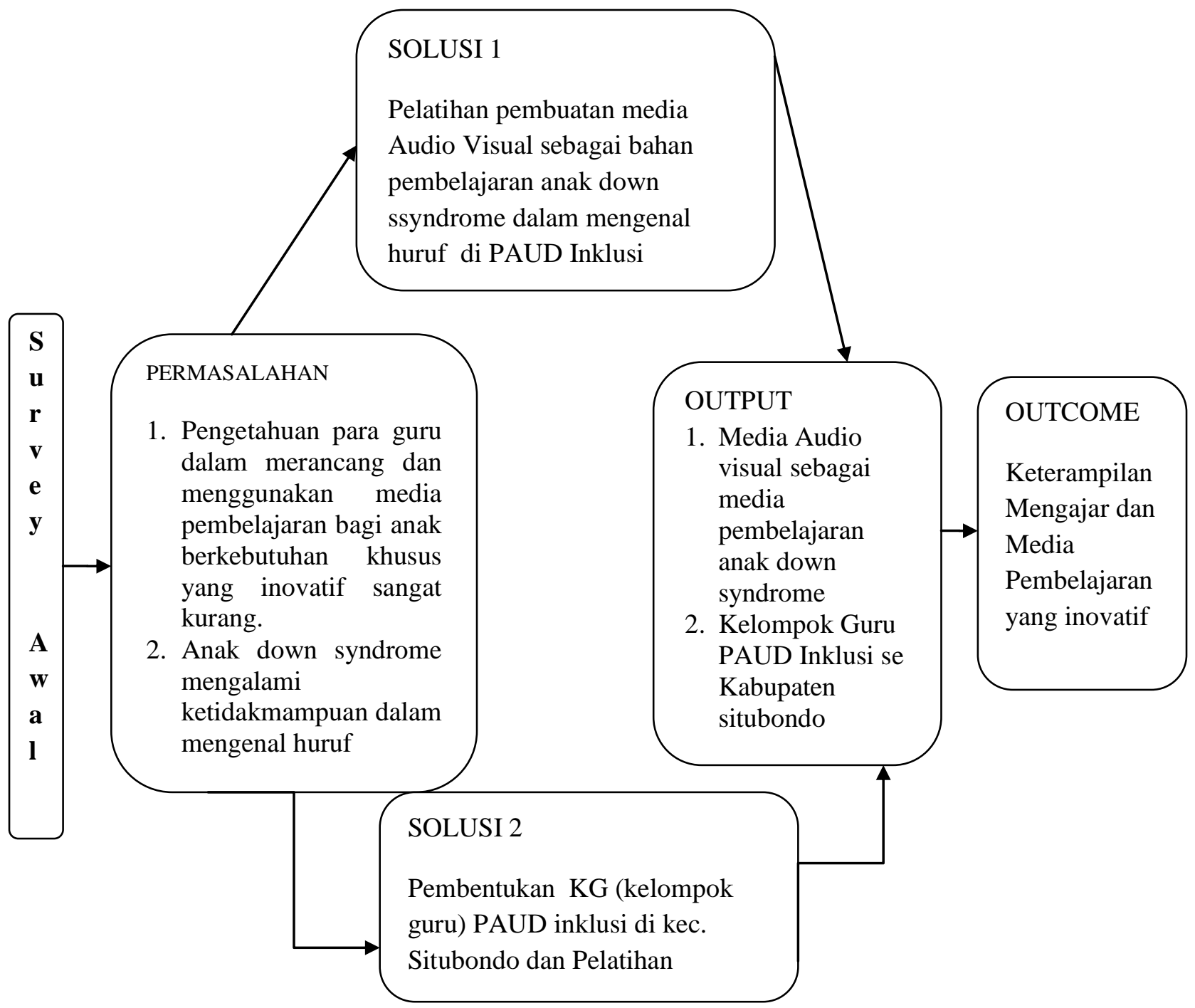

Gambar 2. Gambaran IPTEK yang akan dilaksanakan pada Mitra 


\section{INTEGRITAS : Jurnal Pengabdian}

Vol 4, No 1, Juli 2020

ISSN 2580 - 7978 (cetak) ISSN 2615 - 0794 (online)

\section{METODE PELAKSANAAN}

Metode pendekatan yang ditawarkan dalam mengatasi berbagai permasalahan mitra adalah melalui pendampingan bagi guru pendamping dalam membuat media pembelajaran berupa audio visual sehingga siswa downsyndrome bisa lebih mudah dalam menerima pembelajaran yang dinerikan oleh guru teraikait mengenal huruf. Dalam pelaksanaan kegiatan pengabdian ini, metodemetode yang diterapkan adalah sebagai berikut :

\section{Tahapan Persiapan}

Tahap persiapan mencakup beberapa langkah kegiatan yaitu :

a. Observasi awal. Observasi awal dilakukan untuk memilih sekolah yang akan menjadi mitra kegiatan. Dalam hal ini dipilihlah PAUD Inklusikarena sekolah tersebut satu- satunya sekolah inklusi pada jenjang Pra sekolah di Kecamatan Situbondo.

b. Pemilihan pendampingan dan narasumber, Pendampingan disini adalah pelaksana kegiatan pengabdian yaitu 1 orang dosen dan narasumber dalam kegiatan ini yaitu Vidya Pratiwi, M.Pd

c. Penempatan waktu, tempat dan anggota pelatihan.Setelah mitra setuju untuk bekerjasama, maka waktu, tempat dan anggota pelatihan segera ditetapkan.

\section{Tahapan pelaksanaan}

Pelaksanaan kegiatan pengabdian ini adalah selama 2 bulan.Pendampingan pembuatan media audio visual bagi guru PAUD Inklusi pada tahap ini ada 2 kegiatan yaitu :

a. Pelatihan, dalam pelatihan ini yaitu guru paud Inklusi. Pelaksanaan kegiatan pelatihan dilakukan dalam empat kali pertemuan dengan detail sebagai berikut:

- Pertemuan I : Pengenalan dan tujuan kegiatan. Memberikan materi yang dilakukan oleh pelaksanan sendiri terkait penanganan siswa berkebutuhan khusus khususnya down syndrome dan selanjutnya 


\section{INTEGRITAS : Jurnal Pengabdian}

pemberian materi terkait media pembelajaran berupa audio visual oleh Ibu Vidya Prtiwi, M.Pd dengan memberikan teknik pembuatan media pembelajaran dengan mudah bagi guru.

- Pertemuan II : Pelatihan pembuatan media audio visual, peserta di wajibkan untuk membawa laptop dalam pelaksaan kegaiatn pelatihan berlangsung. Kegiatan pertemuan kedua ini guru membuat materi pembelajaran pengenalan huruf dengan baik.

- Pertemuan III : Implementasi pelatihan pembuatan media audio visual yang dilakukan oleh peserta.

\section{b. Pendampingan,}

Dalam kegiatan ini guru paud di bentuk kelompok- kelompok agar mempermudah dalam pendampingan pembuatan media audio visual. Setelah guru di beri tugas dalam membuat media pembelajaran berupa audio visual dengan tema pengenalan huruf kemudian diminta untuk mempresentasikan hasil karya mereka. Setelah kegiatan pelatihan ini guru di minta untuk mengimplementasikan media audio visual kepada anak down syndrome.Dalam pendampingan ini guru membutuhkan waktu yang lumayan lama karena harus memfokuskan anak down syndrome dalam pembelajaran pengenalan huruf dengan menggunkan media audio visual.

\section{Tahap Tindak Lanjut Kegiatan}

Pada tahap ini menindak lanjutdari pendampingan yang dilakukan oleh guru dalam pemberian materi pengenalan huruf dengan menggunakan media audio visual. Tahap tindak lanjut ini meliputi evaluasi dan tindak lanjut pelaksanaan pelatihan pembelajaran terhadap anak down syndrome dengan melihat peningkatan kemampuan dalam mengenal huruf.

Partisipasi mitra dengan program ini dapat berperan aktif untuk menghasilkanmedia pembelajaran bagi siswa Downsyndrome berupa audio visual sehingga siswa berkebutuhan khusus terutama siswa downsyndrome belajar membaca dengan mengenal hurufdengan baik. Mitra PKM dalam hal ini adalah 


\section{INTEGRITAS : Jurnal Pengabdian}

Vol 4, No 1, Juli 2020

ISSN 2580 - 7978 (cetak) ISSN 2615 - 0794 (online)

Stakeholderyaitu guru PAUD inklusi kec. Situbondo. Mitra berperan dalam hal melakukan inventarisasi, menjadi penghubung dan pendukung kegiatan PKM serta berkomitmen untuk melanjutkan kegiatan PKM secara berkelanjutan.Keberlanjutan dari program ini menghasilkan media pembelajaran yang menarik bagi siswa berkebutuhan khusus sehingga akan semakin meningkatkan minat belajar dalam mengenal huruf dan kemampuan mengenal kosa kata di sekolah masing-masing.

\section{HASIL DAN PEMBAHASAN}

\section{Pelatihan Pembuatan media audio visual}

Dari kegiatan pengabdian ini, guru pendamping telah mendapatkan tambahan wawasan tentang menangani anak berkebutuhan khusus khususnya bagi siswa Downsyndrome.Guru mengalami kesulitan terkait pemberian materi terhadap anak downsyndrome dikarenakan pengetahuan para guru dalam merancang dan menggunakan media pembelajaran bagi anak berkebutuhan khusus yang inovatif sangat kurang.Anak down syndrome mengalami ketidakmampuan dalam mengenal huruf.

\section{Pelaksanaan Kegiatan}

Rancangan mekanisme pelaksanaan kegiatan PKM ini dilakukan dengan 3 tahapan yaitu tahapan persiapan, tahapan pelaksanan dan tahapan tindak lanjutkegiatan. Kegiatan-kegiatan atau aktivitas-aktivitas dari masing-masing tahapan adalah sebagai berikut :

\section{Tahapan Persiapan}

\section{a. Observasi awal}

Pada tahap ini, pelaksana program menghasilkan persetujuan dengan mitra terpilih yaitu PAUD Inklusi Anggrek yang ada di kecamatan situbondo.Permasalahan utama adalah Pengetahuan para guru dalam merancang dan menggunakan media pembelajaran bagi anak berkebutuhan khusus yang inovatif sangat kurang dan pemhaman pengenalan huruf anak down syndrome sangat rendah. Setelah 


\section{INTEGRITAS : Jurnal Pengabdian}

\section{ISSN 2580 - 7978 (cetak) ISSN 2615 - 0794 (online)}

menganilisis permasalahan serta solusi untuk memecahkan masalah tersebut, agar guru- guru PAUD inklusi lebih inovatif dalam pemberian materi baik bagi siswa reguler maupun siswa berkebutuhan khusus.

b. Pemilihan pendampingan dan narasumber

Pada tahap ini pelaksana kegiatan menjadi narasumber dalam materi awal terkait penanganan siswa Down Syndrome dan untu materi pelatihan pembuatan media audio visual pelaksana menunjuk narasumber 1 orang dosen yang bidang fokus keahliannya di bidang teknologi pendidikan yaitu Vidya Pratiwi, M.Pd.

c. Penempatan waktu

Kegiatan pelatihan ini dilaksanakan selama kurang lebih 1 bulan lamanya yaitu dilaksanakan pada bulan november. Kegiatan ini bertempat di PAUD inklusi anggrek. Anggota dalam kegiatan ini yaitu guru paud inklusi anggrek yang ada di kecamatan situbondo.

\section{Tahap Pelaksanaan}

\section{a. Kegiatan Pelatihan}

- Pertemuan I

Pelaksanann pada kegiatan awal yaitu dengan materi penanganan anak berkebutuhan khusus di sekolah Inklusi yang dilakukan oleh pelaksana sendiri sebagi narasumber. Selanjutnya dengan pemberian materi kedua terkait pembuatan media audio visual oleh narasumber Vidya Pratiwi, M.Pd.kegiatan berikutnya yaitu pelaksana melakukansesi tanya jawab terkait kendala yang di hadapi oleh guru dalam pendampingan siswa berkebutuhan khusus, khususnya anak down syndromeDari hasil pembahasan permasalahan yang di hadapi oleh guru, mereka tampak semangat kembali dalam pendampingan anak berkebutuhan khusus dengan memberikan materi pembelajaran yang inovatif agar siswa berkebutuhan khusus bisa menerima materi pembelajaran dengan baik. 


\section{INTEGRITAS : Jurnal Pengabdian}
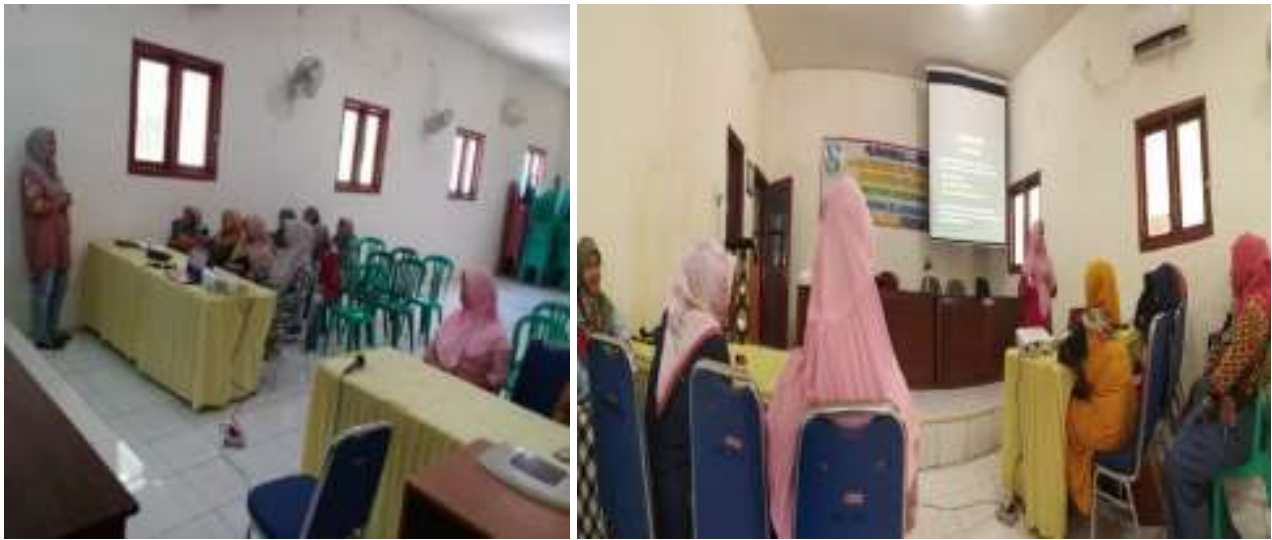

Gambar 2. Narasumber Memberikan Materi

\section{- Pertemuan II}

Implementasi dari hasil pelatihan yang sudah dipelajari pada hari sebelumnya, selanjutnya di implementasikan dalam bentuk praktek, para peserta wajib membawa laptop ketika pelaksanaan kegiatan. Pada kegiatan praktek masih banyak peserta yang kebingungan dalam langkah pembuatan media audio visual. Waktu yang telah direncanakan pada kegiatan penerapan berjalan sesuai dengan jadwal yang sudah disepakati pada awal kegiatan, bahkan peserta meminta perpajangan waktu. Setelah kegiatan pelatihan ini peserta diminta untuk mengirim hasil prakteknya kepada tim pelaksana, yang nantinya akan menjadi bahan evaluasi oleh tim pengabdi. Pendampingan dalam pembuatan media audio visual.

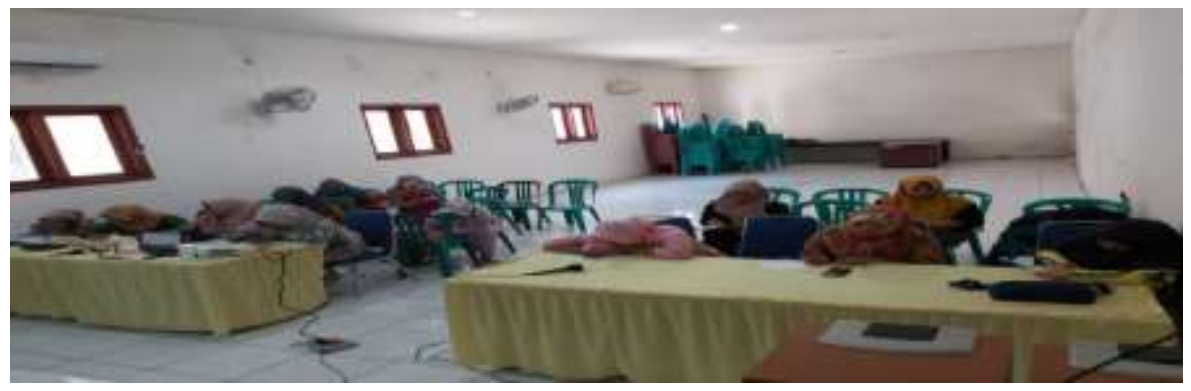

Gambar 3.Peserta dalam kegiatan pelatihan

- Pertemuan III

Kegiatan pada pertemuan ketiga peserta diminta untuk mempresentasikan hasil pembuatan media audio visual dengan tema pengenalan huruf yang sudah di buat pada pertemuan sebelumnya. Setelah peserta 


\section{INTEGRITAS : Jurnal Pengabdian}

Vol 4, No 1, Juli 2020

ISSN $2580-7978$ (cetak) ISSN 2615 - 0794 (online)

mempresentasikan hasil karyanya selanjutnya dilakukan evaluasi bersama terkait media audio visual. Pada akhir kegiatan dilakukan evaluasi berupa pengisian angket yang dilakukan oleh peserta tentang kegiatan pelatihan berlangsung.

\section{b. Pendampingan}

Setelah kegiatan pelatihan ini guru di minta untuk mengimplementasikan media audio visual kepada anak down syndrome. Dalam kegiatan ini pelaksana mengikuti kegiatan pembejaran yang dilakukan oleh guru dengan pemberian materi pengenalan huruf menggunkan media audio visual baik kepada siswa reguler maupun siswa berkebutuhan khusus, khususnya anak down syndrome. Pelaksana melihat kondisi anak down syndrome apakah mengalami peningkatan dalam pembelajaran, yang semula mengalami kesulitan dalam mengenal huruf yang kemudian mudah memahami pengenalan huruf dengan menggunkaan media audio visual. Dalam wawancara dengan Kepala sekolah pemilihan media pembelajaran yang tepat dan sesuai dengan tujuan pembelajaran yang hendak di capai itu sangat penting, terlebih pembelajaran bagi anak berkebutuhan khusus. Anak down syndrome merupakan anak yang mengalami keterbelakangan mental yang disebabkan penyimpangan jumlah kromosom. Hal ini berpengaruh terhadap cara belajar anak, cara guru membelajarkan anak. Guru memberikan pembelajaran kepada anak down syndrome secara individual yang disesuaikan dengan kebutuhan yang dimiliki masing- masing anak.

Dalam pendampingan ini guru membutuhkan waktu yang lumayan lama karena harus memfokuskan anak down syndrome dalam pembelajaran pengenalan huruf dengan menggunkan media audio visual. Siswa down syndrome memiliki fisik yang berbeda dari siswa lainnya karena kelainan kromosom yang mengakibatkan fisik siswa down syndrome berbeda salah satunya yaitu pengucapan siswa down syndrome tidak begitu jelas seperti orang cadel dan kata yang diucpkan hanya kata yang diujungnya saja. Faktor penghambat lainnya yaitu fokus anak down syndrome mudah mengalihkan, maka guru harus mampu mengalihkan fokus siswa down syndrome ke pembelajaran dengan media audio 


\section{INTEGRITAS : Jurnal Pengabdian}

Vol 4, No 1, Juli 2020

ISSN $2580-7978$ (cetak) ISSN 2615 - 0794 (online)

visual. Dengan adanya media audio visual anak down syndrome bisa teralihkan karena adanya gambar - gambar dan warna yang ada di media audio visual tersebut.

\section{Tahap tindak lanjut}

Tahap ini terdiri dari evaluasi dan tindak lanjut dari pelaksanaan pelatihan. Kegiatan evaluasi dilakukan setelah kegiatan pelatihan dilaksanakan yaitu di kampus 2 universitas abdurachman saleh. Kegiatan evaluasi ini dengan melihat hasil pengisian angket yang di berikan oleh pelaksana kepada peserta. Dengan melihat hasil angket tersebut terlihat bahwa peserta sangat antusias dalam kegiata pelatihan ini karena mendapatkan pengalaman baru dan ilmu baru sehingga sangat membantu sekali dalam pemberian materi yang inovatif terhadap siswa reguler maupun siswa berkebutuhan khusus. Selain itu kegiatan evaluasi ini digunakan sebagai tolak ukur untuk melakukan pengabdian selanjutnya bagi guru paud inklusi.

\section{Luaran yang Dicapai}

Luaran yang dicapai melalui kegiatan Pelatihan Pembuatan Media Audio Visual bagi Guru PAUD Inklusi untuk siswa Down Syndrome di Kecamatan Situbondo adalah sebagai berikut:

1. Pelatihan pembuatan media audio visual bagi guru guru PAUD inklusi untuk siswa down syndrome

2. Publikasi ilmiah berupa artikel jurnal ilmiah nasional terakreditasi.

\section{KESIMPULAN DAN SARAN}

Dari kegiatan pengabdian ini dapat disimpulkan bahwa diperlukan adanya pelatihan bagi guru dalam pembebuatan media pembelajaran yang inovatif bagi anak berkebutuhan khusus, khususnya anak down syndrom. Media pembelajaran audio visual sangat efektif dalam pemberian materi pengenalan huruf bagi siswa down syndrome maupun siswa reguler.Proses pelatihan pembuatan media audio visual bagi guru PAUD Inklusi di kec. Situbondo menunjukkan respon yang positif dengan antusiasnya guru memberikan pertanyaan kepada narasumber dan 


\section{INTEGRITAS : Jurnal Pengabdian}

Vol 4, No 1, Juli 2020

ISSN $2580-7978$ (cetak) ISSN 2615 - 0794 (online)

pelatihan ini guru lebih inovatif dalam pembuatan media pembelajaran. Selanjutnya adanya pembentukan kelompok bagi guru pendamping anak berkebutuhan khusus untuk jenjang Pra sekolah.

Kegiatan pelatihan ini sangat bermanfaat sekali bagi guru Paud Inklusi. Maka dari itu akan lebih baik lagi jika guru dapat mengembangkan media pembelajaran yang lebih inovatif sebagai bentuk tindak lanjut dari pelatihan yang telah dilakukan.

\section{DAFTAR PUSTAKA}

Ariani, Y. (2012). Perubahan dan Pelepasan Fonem Dalam Kegiatan Bercakapcakap Pada Anak Down Syndrome di Sekolah Luar Bias Cahaya Mentari Kartasura.

E.Kosasih. 2012. Cara bijak Memahami Anak Berkebutuhan Khsusus. Bandung: Yrama Widya

Smith. 2006. Inklusi, Sekolah Ramah Untuk Semua. (Penerjamahan Denis, Ny. Enrica). Bandung: Nuansa 